Research Article

\title{
Surveying the Impact of Authentic and Pragmatic Marketing by Paradigm Shift on Brand Authenticity: A Case Study of Selected Islamic Azad Universities (Anzali, Tehran Markaz, and Tonekabon)
}

\author{
Zohreh Ali Esmaeli $\mathbb{D}^{1},{ }^{1}$ Bahram Kheiri $\mathbb{D}^{2},{ }^{2}$ and Farzin Farahbod $\mathbb{D}^{1}$ \\ ${ }^{1}$ Marketing Department, Rasht Branch, Islamic Azad University, Rasht, Iran \\ ${ }^{2}$ Department of Marketing Management, Azad University at Tehran Markaz Branch, Tehran, Iran \\ Correspondence should be addressed to Bahram Kheiri; bahramkheiri@gmail.com
}

Received 9 October 2019; Accepted 8 January 2020; Published 21 August 2020

Academic Editor: Alessandra Agostini

Copyright (c) 2020 Zohreh Ali Esmaeli et al. This is an open access article distributed under the Creative Commons Attribution License, which permits unrestricted use, distribution, and reproduction in any medium, provided the original work is properly cited.

\begin{abstract}
The contextual changes of the present age have altered the former order of personal and social relations in such a way that the creation of a new order is accompanied by an epistemic crisis; the crisis of knowledge of new relationships has rendered past valuations inefficient and invalid. In this regard, Kotler considers authenticity as the most influential element in this era of achieving sustainable development and customer trust, and since the production of university knowledge is the key to sustainable development, today it is faced with quality issues. This study aimed to investigate the effect of two marketing strategies, namely, authentic marketing and pragmatic marketing, through paradigm shifts as a solution to the epistemic crisis of brand authenticity. The research method of this study is based on quantitative and descriptive survey. The case study consists of Iranian students of Islamic Azad Universities (IAUs) stratified random sampling and sample size based on Morgan table were 385 people. Data were collected and distributed by questionnaire. The structural equation modeling technique with partial least squares approach and SmartPLS2 software were used for data analysis. The findings indicate that both authentic marketing and pragmatic marketing are more effective on brand authenticity through paradigm shift.
\end{abstract}

\section{Introduction}

In 1965, Kotler considered the transaction as a "social exchange" process in a paper that describes the concept of marketing as a social exchange process. Accordingly, the purely economic viewpoint of marketing is a mistake of proximity and it hinders the development of marketing science [1]. Also, in his book entitled the third age of marketing, Kotler calls marketing as the era of value creation, and marketing managers, instead of treating people as consumers, regard them as people with the brain, heart, and soul; marketing is not a process that only marketers follow in their relationship with the consumer [2]. Consumers also use marketing in their daily communication. Third-age marketing sees customer as a human being; the human being has four basic elements: a body, a mind that has the ability to think and analyze independently, the heart that can feel the emotions, and the spirit or philosophical center of the body; hence, he considers authenticity or credibility as the most effective element of the new age in creating sustainable development [2].

In a world full of complexity, customers are looking for companies that meet their deep needs for social, economic, and environmental justice in mission, vision, and values. Not only do they seek to meet their functional and emotional needs in the products and services they choose but also meeting spiritual needs is important for them. Third-age marketing moves the concept of marketing to ideals, values, and spiritualties and believes that consumers are perfect people and their needs and expectations should not be 
ignored. Therefore, third-age marketing combines "emotional" marketing with "spiritual" marketing [2].

In the book Evolution and Evaluation, Sheth and Sisodia [3] explain the evolution of marketing concepts in two aspects of philosophy of science and the universe. Cultural marketing is the second most important marketing element of the third age. Third-age marketing is an approach that does not overlook the concerns and interests of global citizens. Marketers of the third age must understand the problems of the community that are related to their business [2]. The concept of community interest is considered in the new definition of the 2008 American Marketing Association. According to this definition, marketing is a set of activities and processes for establishing communication, supply, and exchange of proposals that are valued for consumers, clients, partners, and society [2].

How can companies create value in their business models? As a response to this fundamental question, Richard Barrett believes companies can look at levels of spirituality in their business models, like humans. He found that human level of spiritual motivation can be considered in the mission, vision, and value of companies [4]. The warning of Iranian economists to the crisis of value created in Iranian consumer's desire to constantly buy foreign products, which includes types of products from low-level needs to social situations, makes it necessary to redefine the creation of a new way of producing value in Iranian society [5]. Various studies on Iranian universities highlight the existence of significant challenges and ambiguities in its brand validity, for example, investigating the attitude of faculty members [6].

Salehi Omran found that one of the most important reasons for faculty members' migration is driving factors such as low income, feeling of discrimination and inequality in society, dissatisfaction resulted from injustice, and job insecurity and stressors which are the causes of depression [6].

In the realm of paradigms, scientific riddles are made or solved. Cowan says as long as the service paradigm is sufficient to solve the riddle, but when you can no longer serve and the methods, concepts, metaphysics, and tools, norms that constitute the paradigm lose their effectiveness; at this time, scientists are so unhappy with their scientific work that they envy the clowns, as the physicist Koven Wolfgang quotes. It is here that the paradigm is in crisis and the fields of paradigm rotation and the new scientific revolution are formed [8].

Given today's customers' need for authentic values and the inefficiencies of existing paradigms to gain customer trust and producing sustainable value, the inefficiency of the paradigm in the Iranian higher education system in producing the original brand of this study examines two original marketing strategies: first authentic marketing in order to construct and deepen concepts through dialectics in language based on social platforms and the latter with pragmatic marketing in order to achieve authenticity in practice through the experience of theoretical reason in social or dialectical practice, which is examined by the mediating variable of paradigm shifts (from object-based ontology to phenomenology of existence) to their effect on the original brand.

\section{Review of Literature}

2.1. Theoretical Background. According to the Oxford Dictionary, authentic means "original and without a copy; genuine" [9]. In marketing, it means the same; it means creating a dialogue between your brand and your audiences that are natural and real. It is not necessarily true or ethical, as many people believe; it is a kind of strategy that you can use to build deeper communities based on trust and empathy. Authenticity is essential for a new business [10], which uses the Latin word "authenticus" and the Greek word "authentikos" meaning "acceptability, credibility, trust, and not imaginary, false, or imitation and in accordance with the principle." [11] This is what you share. The credibility is to believe in your character, writer, or company [12].

The brand's position alone is not enough. Completion of this process requires a distinction between authenticity for the human soul, which creates a sustainable value in the economy, society, and environment; hence, it is the only element that affects third age of honesty, authenticity, and credibility marketing [2]. A new concept of consumer brand credibility suggests that a credible brand is trustworthy, cares for its consumers, helps them define and build their identity, and represents continuity from the past to the future. [13]. Because their credible brands are a meaningful source of identity building, they must have credible behaviors [14]. Valid brands are real, reliable, and meaningful [10]. Credit is increasingly recognized as a desirable brand attribute. Brand originality refers to a brand that is honest and realistic [10] and distinguishes its credible brand through intimacy, commitment to quality, and relevance to its heritage [12]. Valid brands can have the ability to have the ability to communicate with consumers at the emotional level through their quality symbols [13]. A new concept of credible brand indicates that a credible branding brand for consumers is helping them define and build their identity and represent continuity from the past to the future [13]. Valid consumption is suitable for a wide range of consumer objects and activities that have the potential to create meaning [15]. Significant investments have been made in developing brand values and consistently favorable behavior over time [13]. Since valid brands are defined as symbolic resources [14] that help consumers define the meaning of their lives [11], they benefit from them and have a competitive advantage in terms of building strong relationships with consumer brand $[13,15]$; the impact of brand originality on the emotional affiliation of a consumer is different in a variety of situations [13]. Despite high level of agreement in the correct relationship with consumer behavior and its relation to truth, integrity, and transmission of meaning to consumers, literature is characterized by a diverse and divided approach, and the focus of attention is to be considered in an attempt to accept a generally accepted notion. Given this view [14], the nature of credit in consumption is debatable. "This challenge extends to the field of brand, while there is still a lack of a general definition of credit [13].

The marketing and consumer research literature acknowledges that attempts to consume credibility are due to the loss of traditional sources of meaning and personal 
identity linked to postmodernity $[14,16,17]$. Credibility, as an idea expressed in philosophy and literature, was created in Europe in the 18th century. But moreover, there were a number of widespread and interwoven developments, all of which were related to modernity, which is a complete expression: the slow recession of belief in the cosmic order with the fixed and undeniable social roles, the idea of coping with the individual's autonomy (with his claim for inner depth, dignity, and self-responsible liberty), and the emergence of capitalism, labor, wage, and authority of science and enlightenment demand rationality [18]. The key point is that these aspects of modernity were prerequisites for stimulating ideal credibility. In other words, this originality was a product and a reaction against modern life. In this regard, authenticity is like Orthodox religion. Jean-Jacques Rousseau, a philosopher and novelist of the eighteenth century, pointed out each of the authentic elements: (1) the concept is that we all have a unique and authentic principle (2) that exists within us (3) must be discovered by ourselves (often in terms of nature) and (4) what we want to express, even in (5) the negotiations of social agreements [18], for example, Holt [19] explained that Adorno "sees the danger of this term in accepting it by those who continue to believe it and experience an imaginary reality that they share through the power of communication."

This interest in "interconnectivity" requires that we, by choosing interpretive methods, understand human behavior. Human science should not be a model of natural science but should find ways to understand and interpret human communication. These paths must be "hermeneutics "or" interpretational "(more like a conversation) [20].

Postmodern society is, namely, characterized by fragmentation, confusion, emptiness, alienation, and by a crisis of morality and identity. Hence, people have become more concerned with identity, meaning, and values [21] but also with nostalgia and history. By conceiving authenticity as constructed and thus as an experience or as a perception, constructivists overcame some dilemmas based on the assumption that authenticity can be experienced and judged only from the "outside"-from a historical, cultural distance with intellectual proficiency (of anthropologists or curators in museums). This discussion is obfuscated by another important question, namely, to what authenticity actually pertains (i.e., what can be authentic). Here, Wang [22] draws a sharp distinction between the authenticity of objects and existential authenticity which can be entirely unrelated with each other. For him, existential authenticity is not objectbased but activity-based and can be divided into two dimensions: intrapersonal (bodily feelings) and interpersonal (self-making). In a similar vein, Steiner and Reisinger [23] claim that existential authenticity and object-based authenticity are entirely different concepts and cannot be explored concurrently. Apart from introducing two basic types of authenticity (i.e., object-based and existential), these diverging views also reflect the incommensurability of different epistemological and philosophical positions that have a stake in the conceptualization of authenticity. The "liberation" of existential authenticity from object and place, namely, relies on existentialist and phenomenological traditions [24].
Sen and his colleagues [25] relied on a field experiment involving a real-world instance of corporate philanthropy to shed light on both the scope and limitations of the strategic returns to corporate social responsibility (CSR). In particular, the authors demonstrate that the impact of CSR in real world is not only less pervasive than what has been previously acknowledged but also more multifaceted than what has been previously conceptualized. The findings indicated that contingent on CSR awareness was rather low, and stakeholders did react positively to the focal company not only in the consumption domain but also in the employment and investment domains as well. Stakeholder attributions regarding the genuineness of the company's motives moderated these effects.

2.2. Authentic Marketing. Authentic marketing is a strategy for organizations to validate their business goals in a credible action [26]. It seeks to increase brand's desirable characteristics, which requires sustainability of capital resources in developing brand value and extending this behavior over time [13]. Because the symbolic source is helping the consumer in his definition and the meaning of his life, in this strong bond, the brand gains trust and growth [27].

In this study, authentic marketing will be surveyed in four dimensions: authentic marketing paradigm, authentic value, social platform development, and authentic marketing mix.

Companies may derive their promised legitimacy from the interests of parties in conversational relations; this is the concept of rhetoric in Heidegger's view [28].

Because of the interference of the interpretive mentality with the use of dialectics, truth may not be derived from method in philosophical hermeneutics, that is, through questionable answering to the issue at hand [29].

It is also possible to understand the meaning of interpretive approach through recognition of conceptual approach and phenomenology that are considered as interpretative approaches. The conceptual method of interpretive approach is an attempt to reveal meaning; there is no real starting point for achieving meaning, since each understanding contains the previous understanding (hermeneutic period) [30]. Based on an extensive review, Hollebeek and Mackey [31] conceptualized DCM as the creation and dissemination of relevant, valuable brand-related content to current or prospective customers on digital platforms to develop their favorable brand engagement, trust, and relationships (vs. directly persuading consumers to purchase). They also developed a conceptual framework that identifies important consumerbased DCM antecedents, including uses-and-gratifications(U\&G-) informed functional, hedonic, and authenticitybased motives for DCM interactions. DCM's first tier, intrainteraction consequences, includes consumers' cognitive, emotional, and behavioral engagement that fosters brand-related sense making, identification, and citizenship behaviors, respectively. These in turn trigger DCM's second tier, extrainteraction consequences, of brand trust and attitude, which successively contribute to the development of DCM's third tier: value-based consequences of consumer and firm-based brand equity. 
Authentic values are the opposite of Maslow's pyramid. In fact, creative people have a strong belief in Maslow's reverse pyramid. Spirituality's valuable aspects are immaterial life, enduring realities in creative communities, and businesses that respond to their spiritual needs. The future value proposition of marketing is the supply of spirituality. Value-added business modeling is the new infrastructure of third-age marketing [2].

One way for collective value creation appropriate to customer creativity is a business platform. Platforms create value through interaction; they create and shape interaction between external producers and external consumers. An important part of the role of the platform is to create the infrastructure for the formation of interactions and to determine the framework and rules governing these interactions [32]. Social media is an online application, platform, or media that facilitates interactions, collaborative work, or content sharing [33]; interactions with social media fundamentally change the dynamics of brand and customer communication, and the motivation for developing user-generated content (UGC) on social media also changes [34]. Authentic marketing is a type of postmodern marketing that emphasizes the phenomenology of consumer existence. In postmodern marketing, customers pay for the symbolic meaning of the product, so the main marketing mix is product enrichment, price paradox, presence of sales, and participation in product promotion [35].

2.3. Pragmatic Marketing. The word "pragmatism" in Farsi has been translated into "religion of originality of practice," "practical expediency," "pragmatism," "correction," "expediency," and "scientific aptitude." The word is derived from the Greek root Prassein meaning to do. Pragmatism is a method of solving or evaluating rational problems, as well as a theory of the kinds of identifications we are prone to acquire. Called pragmatism, or principle of action, this school considers the truth is in practice which has benefit and, in other words, the meaning that which is in our mind must have better results in action [36].

Pragmatic marketing is examined in this research with four dimensions: pragmatics, problem-based, evolutionary product, and strategic management and pragmatic marketing. "Pragmatic-oriented" has a conceptual footprint: we provide practical and meaningful solutions to the problems that product managers face [37].

Pragmatic marketing is a product development process based on experience planning adaptability, retesting, and readaptability as long as the final result, both theoretically and practically, has evolved as a better product. The first step in pragmatic marketing is to discover what the customer wants to buy. Pragmatic marketing involves understanding market problems by conducting interviews with customers as well as potential customers to understand their critical issues. This measure is also important to understand why potential customers and clients have evaluated a product in a particular way, and it also includes an assessment of the strengths and weaknesses of competition [38].

The strategic management process of pragmatic marketing is a framework; this pragmatic marketing framework improves a standard language for one's entire product team and provides an outline of the key activities needed for profitability and marketability of problem-oriented products, which includes the following steps: market, focus, business, planning, empowerment, and support [39].

2.4. Paradigm Shift. The shift in paradigm is reminiscent of Thomas Cowan and his famous book the Structure of the Scientific Revolution [40]. Paradigm is the epistemic and social horizon and space that provides the grand parachute rotational pattern. Basic concepts are important in every paradigm. Every paradigm contains values, norms, and tools that become important to us and turns into insignificant tools. The set of these tools, norms, assumptions, concepts, and habits are formed in a cyclical context called the paradigm, as Cowan puts it. The community of researchers and scientists breathe in a paradigm, and their science takes place in the paradigm [8]. The business paradigm is a set of rules that delineate boundaries and illustrate how to act and solve problems within it.

Inspired by the historiography of science, Jules Arthur Barker proposed a paradigm shift. With the paradigm shifting, the return to the zero point is happening and all competitors have to start the game off. Newcomers can seize opportunities to compete with industry players and win. The decline of Swiss watchmaking and the emergence of Japanese watchmaking is an example of this type of change [8]. The growing trend of consumers working together has impacted businesses. Companies no longer have complete control over their brand because they are competing with the collective power of consumers. This growing consumer trend that restricts marketers' activity is what Vip Forrest has called brand theft. Nowadays, companies have to collaborate with their consumers. This starts when marketing managers listen to their consumers to understand their minds. When consumers play a key role in creating value through the cocreation of products and services, more advanced partnerships occur [2].

In today's age, when word-of-mouth advertising has become a new medium and consumers trust strangers in their community more than corporations, brands without authenticity have no chance of survival. There are also lies and deception on social media, but due to the collective wisdom of consumers, it will quickly be exposed [2].

For over 60 decades, marketing concepts have been vertical. In order to regain trust, a consumer trust system must be designed and implemented. The new system of gaining consumer confidence is horizontal. The time has come for the end of the divide between marketers and consumers [2]. Consumer growth, out-of-structure changes that have limited the ability for consumers to control consumers, and the new wave technology have made marketers face the crisis of responding efficiently to new relationships. Accordingly, the present study explores the effect of changing ontology from object-oriented to phenomenology of existence and changing ontology to dialectics in language and practice in the context of sustained customer interaction [41]. 
"Creating originality in marketing" is partly seen as a paradox, and "all human economic entities are cognitively fraudulent-meaning within themselves without credibility-and yet its output can be phenomenologically real, that is, it is perceived as valid by the people who buy it" [41].

The existential phenomenological paradigm has a contextual (context-centered) perspective in which experiences emerge as a pattern out of context. Ontologically, the experience and the world can be understood as a coherent unit that underlies the burden of social, empirical, and interpersonal issues with the individuals or groups who see it. Epistemologically, it has a subjective negotiating position. That is, it is assumed that the researcher and the subject are interacting in such a way that the findings are interpolated and interpreted in the course of the research. In this active and passive approach, cognition is one and knowledge is produced and reproduced in an interactive, relational, and contingent process. The knowledge generated in the interaction process has been evaluated and rethought, and as a collaborative product, it has helped to explain and understand the social world of the subjects. The logic of the research is explanation, interpretation, and rethinking, meaning that the researcher seeks to extract and understand the pattern that emerges from the context. It is a holistic research strategy that relates the relevant descriptions of everyone's experiences to the overall context of the world of life [20].

The existo and existee verb in Latin means leaving from appearing. The term is also common to being and ontology, but it refers to being aware of a reality in the philosophies of existentialism; in other words, existence refers to the particular way of human existence and from existentialism to the authenticity of existence. Kant's and Habermas's knowledge entails adopting a "dialectical approach" that emphasizes the unity and plurality of rational knowledge. In Kant's view, any human knowledge, whether theoretical or practical, requires rational justification and a passage of critique. And he deduced the principles of theoretical and practical reason in a transcendental way from within human experience and cognition. These principles are in fact the general, necessary, and prior conditions of any possible experience [42]. Drawing on these articles, the authors articulate what researchers can do to break boundaries and enhance the impact of their research. They also indicate why engaging in boundarybreaking work and enhancing the breadth of marketing's influence is good for both individual researchers and the fields of consumer research and marketing [8].

The new ecology of learning, in the face of its technological and technological practices, reveals profound paradigm shifts that have broad dimensions of thought, communication, behavior, and culture. Previous conventional training has been subject-oriented and cognitivebased, while new paradigms are process-oriented and communication-based. Closed, elitist, and one-way teaching patterns (one-way and vertical transfer of information from professor to student) are transitioning to open, inclusive, two-way, and horizontal interactive patterns of free information exchange. $84.2 \%$ of the respondents perceive corporate culture as a threat to academic authenticity [8].

\section{Model}

The conceptual model derived from qualitative research is data-based that overlaps with in-depth interviews with marketing experts and those in other fields (economics, philosophy, sociology, and psychology), concepts, coding, and analysis of modern day articles and theories. The research model is shown in Figure 1.

\section{Hypotheses}

There are three views on the concept of originality: objective, constructive, and existentialist. Objective perspective refers to authenticity as an objectively measurable quality of an entity that is evaluated by experts. According to the constructivist view, credibility is a prediction of consumer beliefs, expectations, and perspectives on an entity [22]; the existentialist perspective considers authenticity as belonging to the self rather than to the external entity [41]. Kolar and Zabkar [41] examined it as objective and existentialist approaches. The model of this study considers the effect of two marketing strategies of authenticity: the original marketing being a postmodern marketing with the existentialist perspective of authenticity and pragmatic marketing being a pragmatist marketing that takes the objective view of authenticity which deals with language and practice through paradigm shifts to phenomenology of existence with epistemology.

\subsection{Main Hypotheses}

(1) Authentic marketing has a significant influence on the paradigm shift.

(2) Pragmatic marketing has a significant influence on the paradigm shift.

(3) The paradigm shift has a significant influence on the original brand.

(4) Original marketing has a significant influence on the original brand with the mediating role of paradigm shift.

(5) Pragmatic marketing has a significant influence on the original brand with the mediating role of paradigm shift.

\section{Methods}

The present study is a quantitative research in terms of approach, in which the researcher collects data with predetermined tools that result in the statistical data, and is of a descriptive type. In descriptive research, the researcher seeks out how and what he wants to know about the phenomenon or variable. In other words, this study examines the status quo and systematically describes its current status, explores its features and traits, and examines the relationship between variables if necessary [44]. Since the purpose of this study is to describe the presentation of a native model for authentic marketing and pragmatic marketing and their interaction 


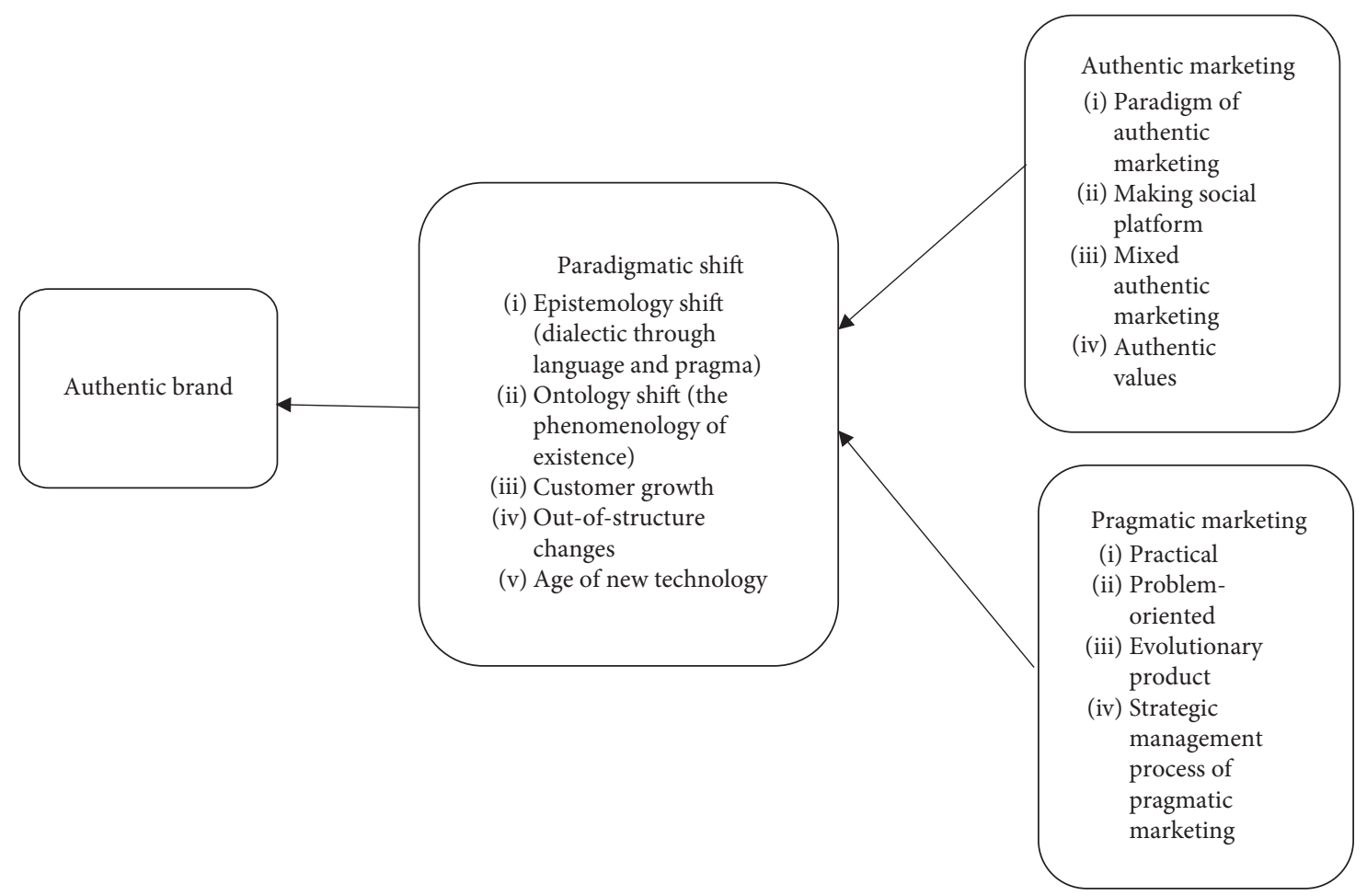

FIGURE 1: The authentic and pragmatic marketing process model [43].

and contrast, this research is considered as a descriptive study.

Surveying is a way to obtain data about the views, beliefs, opinions, behaviors, or characteristics of a group of members of a statistical community through research. More formally, Ross, Wright, and Anderson define surveying as follows: "Surveying is a set of standardized methods used to gather information about individuals, families, or larger collections. Data are collected by asking people who are regularly selected and grouped into sample groups" [45]. Therefore, this research is a survey type. In the quantitative section, the descriptive survey research method was used to evaluate the described phenomenon. The statistical community can be defined as follows: all elements and individuals that share one or more attributes on a given geographic scale (global, regional, local, or spatial) [44]. The statistical population of this study is students of selected Azad universities (Anzali, Tehran Markaz, and Tonekabon). Due to the extent of selected universities, the stratified random sampling method was used. In stratified sampling, the units of the study population are grouped into categories that are more homogeneously variable in order to minimize variations within groups. Then, some samples are randomly selected from each class [44]. Thus, the selected free universities were divided into three classes, Anzali, Tehran center, and Tonekabon, assuming that the students of the free universities were homogeneous. Then, at each free university, student consensus centers such as corridors, campus, and classrooms were selected, and the researcher randomly referred to student consensus centers, and after giving a brief explanation of the research topic, students were asked to fill out a questionnaire if they were university students. And the sample size calculated 385 people based on Morgan's table. Questionnaire was used for data collection. The questionnaire contains several questions about the variables measured by the study population. These questions are constructed using specific techniques as well as scales so that the desired information can be gathered from the study population or sample [44]. The questions in this section are also designed based on a 5-point Likert range.

\section{Finding}

6.1. Descriptive Statistics. Descriptive statistics specify the general characteristics of the population under study and its general characteristics for other researchers. In addition, this knowledge can be used to generalize the results to other communities or to design future research questions for other communities. The descriptive statistics of the research are described in Tables 1 and 2.

6.2. External Model (Measurement Model). Are the questions for measuring variables properly selected? Confirmatory factor analysis (CFA) is used for this purpose such that the factor loading of each marker with its construct has a significant $t$ value at $5 \%$ error level that is to be outside the range of -1.96 and -1.96 , and also the factor loading of each marker with its construct is greater than 0.5 ; this marker is then accurate enough to measure that structure or latent traits [46]. For this purpose, confirmatory factor analysis was performed on questionnaire items as described in Tables 3 and 4 . 
The measurement model of the research variables is presented in two levels of significance and standard coefficients in Figures 2-5.

6.3. Internal Model (Structural Model). An intrinsic model (structural model) describes the relationships between latent variables and determines how much of the variance of a latent variable is explained by other latent variables. Regular indices for testing are used to evaluate the model, including $R^{2}$, path coefficients, and critical coefficients. In Figures 6-9, the internal model of research for research hypotheses in both standard and significant states can be observed.

$R^{2}$, or coefficient of determination, indicates the effect that exogenous variables have on an endogenous variable. Chin [47] identified three values of $0.19,0.33$, and 0.67 as the criterion values for weak, medium, and strong values.

Wetzels et al. [48] identified three values of $0.01,0.25$, and 0.36 as weak, moderate, and strong values for GoF. Tables 5 and 6 show the internal fitting of the model.

It can be observed that the goodness of fit index for all the hypotheses is in the strong range. That is, the internal model is robust enough to test hypotheses and the test results can be statistically reliable.

6.4. Testing Hypotheses. Based on the internal model obtained from the research hypothesis test, the validation or rejection of the research hypothesis will be examined. To confirm or reject the hypotheses, a significant coefficient $(t$ statistic) is used; if the $t$-statistic is greater than -1.96 or less than -1.96 (at $5 \%$ error level), the hypothesis is confirmed and a significant relationship is obtained between the two hidden variables. The results of the hypothesis analysis are presented in Tables 7 and 8.

Commentary: the significance of hypotheses $6,14,22$, 24,35 , and 30 is consistent with Beverland's research [15] that the output of authenticity must be phenomenologically real and internally valid; it is consistent with research findings of Kotler et al. [2] and Frosh [52] that consumers no longer want to consume alone and are themselves the creators of new lifestyles and that creation of the consumers has entered the process of value creation to solve social, cultural, and economic problems and they are no longer passive and have become innovators seeking the spiritual and cultural world; it is also consistent with research results of Zohar and Marshall [53], Davis [18], and Kotler et al.'s research [2] that clergy and spirituality are valuable aspects of immaterial life and sustainable realities in creative societies. Accordingly, it is suggested that to validate their brand internally, selected universities can use students' presence and creativity to produce new styles and innovations in solving social, economic, and cultural issues by shifting the paradigm of phenomenology to make their role as a spiritual and cultural institution in society more desirable.
TABLE 1: Frequency distribution by age category.

\begin{tabular}{lcc}
\hline Age range & Frequency & Percentage \\
\hline $18-28$ years & 337 & 54.5 \\
$28-38$ years & 159 & 25.7 \\
$38-48$ years & 102 & 16.5 \\
48 years and more & 20 & 3.2 \\
Total & 618 & 100 \\
\hline
\end{tabular}

Table 2: Frequency distribution by education level.

\begin{tabular}{lcc}
\hline Education & Frequency & Percentage \\
\hline Bachelor's degree & 197 & 31.9 \\
Master's degree & 351 & 56.8 \\
Doctorate & 70 & 11.3 \\
Total & 618 & 100 \\
\hline
\end{tabular}

TABLE 3: Factor loading and significance of questions (first-order analysis).

\begin{tabular}{|c|c|c|c|}
\hline Variable & Question & Factor loading & Significance \\
\hline \multirow{11}{*}{ Authentic marketing } & AA1 & 0.5 & 13.49 \\
\hline & AA2 & 0.54 & 14.92 \\
\hline & AA3 & 0.62 & 17.46 \\
\hline & $\mathrm{AB} 1$ & 0.76 & 39.49 \\
\hline & $\mathrm{AB} 3$ & 0.51 & 11.94 \\
\hline & $\mathrm{AC} 1$ & 0.80 & 45.69 \\
\hline & $\mathrm{AC} 2$ & 0.86 & 66.21 \\
\hline & AC3 & 0.85 & 66.48 \\
\hline & $\mathrm{AD} 1$ & 0.88 & 93.13 \\
\hline & $\mathrm{AD} 2$ & 0.76 & 37.11 \\
\hline & $\mathrm{AD} 3$ & 0.73 & 33.22 \\
\hline \multirow{11}{*}{ Pragmatic marketing } & BA1 & 0.66 & 25.38 \\
\hline & BA2 & 0.78 & 45.24 \\
\hline & $\mathrm{BB} 1$ & 0.83 & 56.39 \\
\hline & BB2 & 0.83 & 53.59 \\
\hline & BB3 & 0.84 & 56.25 \\
\hline & $\mathrm{BC} 1$ & 0.87 & 40.21 \\
\hline & $\mathrm{BC} 2$ & 0.78 & 39.47 \\
\hline & $\mathrm{BC} 3$ & 0.61 & 18.39 \\
\hline & BD1 & 0.83 & 56.16 \\
\hline & $\mathrm{BD} 2$ & 0.82 & 49.15 \\
\hline & BD3 & 0.85 & 59.72 \\
\hline \multirow{11}{*}{ Paradigm shift } & CA1 & 0.65 & 22.56 \\
\hline & CA2 & 0.58 & 16.89 \\
\hline & $\mathrm{CB} 1$ & 0.74 & 31.63 \\
\hline & CB2 & 0.72 & 28.76 \\
\hline & CB3 & 0.72 & 30.01 \\
\hline & $\mathrm{CC} 1$ & 0.79 & 51.00 \\
\hline & $\mathrm{CC} 2$ & 0.75 & 38.53 \\
\hline & $\mathrm{CC} 3$ & 0.76 & 48.10 \\
\hline & $\mathrm{CD} 1$ & 0.79 & 47.48 \\
\hline & $\mathrm{CD} 2$ & 0.83 & 67.33 \\
\hline & CD3 & 0.76 & 34.55 \\
\hline \multirow{3}{*}{ Original brand } & D1 & 0.89 & 111.84 \\
\hline & D2 & 0.90 & 96.34 \\
\hline & D3 & 0.74 & 28.13 \\
\hline
\end{tabular}


TABLE 4: Factor loading and significance of questions (second-order analysis).

\begin{tabular}{|c|c|c|c|}
\hline Variable & Question & Factor loading & Significance \\
\hline \multirow{3}{*}{ Authentic marketing paradigm } & AA1 & 0.82 & 39.88 \\
\hline & AA2 & 0.84 & 49.95 \\
\hline & AA3 & 0.84 & 40.51 \\
\hline \multirow{3}{*}{ Making social platforms } & $\mathrm{AB} 1$ & 0.81 & 40.22 \\
\hline & $\mathrm{AB} 2$ & 0.73 & 19.68 \\
\hline & $\mathrm{AB} 3$ & 0.81 & 37.29 \\
\hline \multirow{3}{*}{ Authentic marketing mix } & $\mathrm{AC} 1$ & 0.88 & 80.91 \\
\hline & AC2 & 0.93 & 139.68 \\
\hline & AC3 & 0.87 & 50.75 \\
\hline \multirow{3}{*}{ Authentic values } & $\mathrm{AD} 1$ & 0.91 & 113.12 \\
\hline & $\mathrm{AD} 2$ & 0.85 & 49.09 \\
\hline & AD3 & 0.83 & 42.49 \\
\hline \multirow{2}{*}{ Pragmatism } & BA1 & 0.85 & 44.82 \\
\hline & BA2 & 0.92 & 131.40 \\
\hline \multirow{3}{*}{ Problem-oriented } & BB1 & 0.93 & 125.46 \\
\hline & $\mathrm{BB} 2$ & 0.91 & 84.94 \\
\hline & BB3 & 0.92 & 104.45 \\
\hline \multirow{3}{*}{ Evolutionary product } & $\mathrm{BC} 1$ & 0.89 & 78.74 \\
\hline & $\mathrm{BC} 2$ & 0.89 & 68.85 \\
\hline & $\mathrm{BC} 3$ & 0.76 & 31.59 \\
\hline \multirow{3}{*}{ The process of strategic formulation of pragmatic marketing } & BD1 & 0.88 & 78.98 \\
\hline & BD2 & 0.92 & 102.04 \\
\hline & BD3 & 0.93 & 108.89 \\
\hline \multirow{2}{*}{ Epistemological change } & CA1 & 0.91 & 89.58 \\
\hline & CA2 & 0.88 & 56.23 \\
\hline \multirow{3}{*}{ Ontological change } & CB1 & 0.88 & 58.40 \\
\hline & $\mathrm{CB} 2$ & 0.93 & 100.97 \\
\hline & CB3 & 0.94 & 104.96 \\
\hline \multirow{3}{*}{ Consumer growth } & CC1 & 0.86 & 76.88 \\
\hline & $\mathrm{CC} 2$ & 0.84 & 51.63 \\
\hline & CC3 & 0.90 & 97.78 \\
\hline \multirow{3}{*}{ Out-of-structure changes } & $\mathrm{CD} 1$ & 0.83 & 49.37 \\
\hline & $\mathrm{CD} 2$ & 0.90 & 118.03 \\
\hline & $\mathrm{CD} 3$ & 0.85 & 59.01 \\
\hline
\end{tabular}

Commentary: disapproval of hypotheses $7,8,9,15,16$, $17,23,25,31,32,38,39$, with Parker et al.'s research. [32] and Dragon's [54] research that platform is business place. Platforms create value through interaction and new social arrangements that develop concepts over time. It is also not consistent with the research conducted by Ferahbod and Yousefinia [35] that customers pay money for symbolic meanings in the postmodern marketing, indicating that in the study community, building social platforms and making meaningful products do not necessarily have a significant relationship with paradigm shift. In addition, there is no significant relationship between ontology and epistemology on brand originality in this society and further research is needed in these cases.

Hypothesis 1. Original marketing has a significant effect on paradigm shift.
H0: original marketing has no significant effect on paradigm shift.

$\mathrm{H} 1$ : original marketing has a significant effect on the paradigm shift.

The path coefficient of the authentic marketing effect on the paradigm shift is 0.15 and has a $t$ value of 3.40 . The $t$ value for this parameter is calculated to be more than 2.58 . Therefore, the null hypothesis is rejected with $99 \%$ confidence. That is, there is a significant relationship between the authentic marketing and the paradigm shift and the authentic marketing is effective on the paradigm shift. Therefore, this research hypothesis is accepted.

The significant impact of authentic marketing on paradigm shifts is consistent with the results of Kotler [2] and Moulard et al. [49]. The relationship between authenticity and spirit or philosophical center of human and the phenomenon of originality is consistent with the existence of the phenomenon, showing that authentic marketing of university is effective on the community 


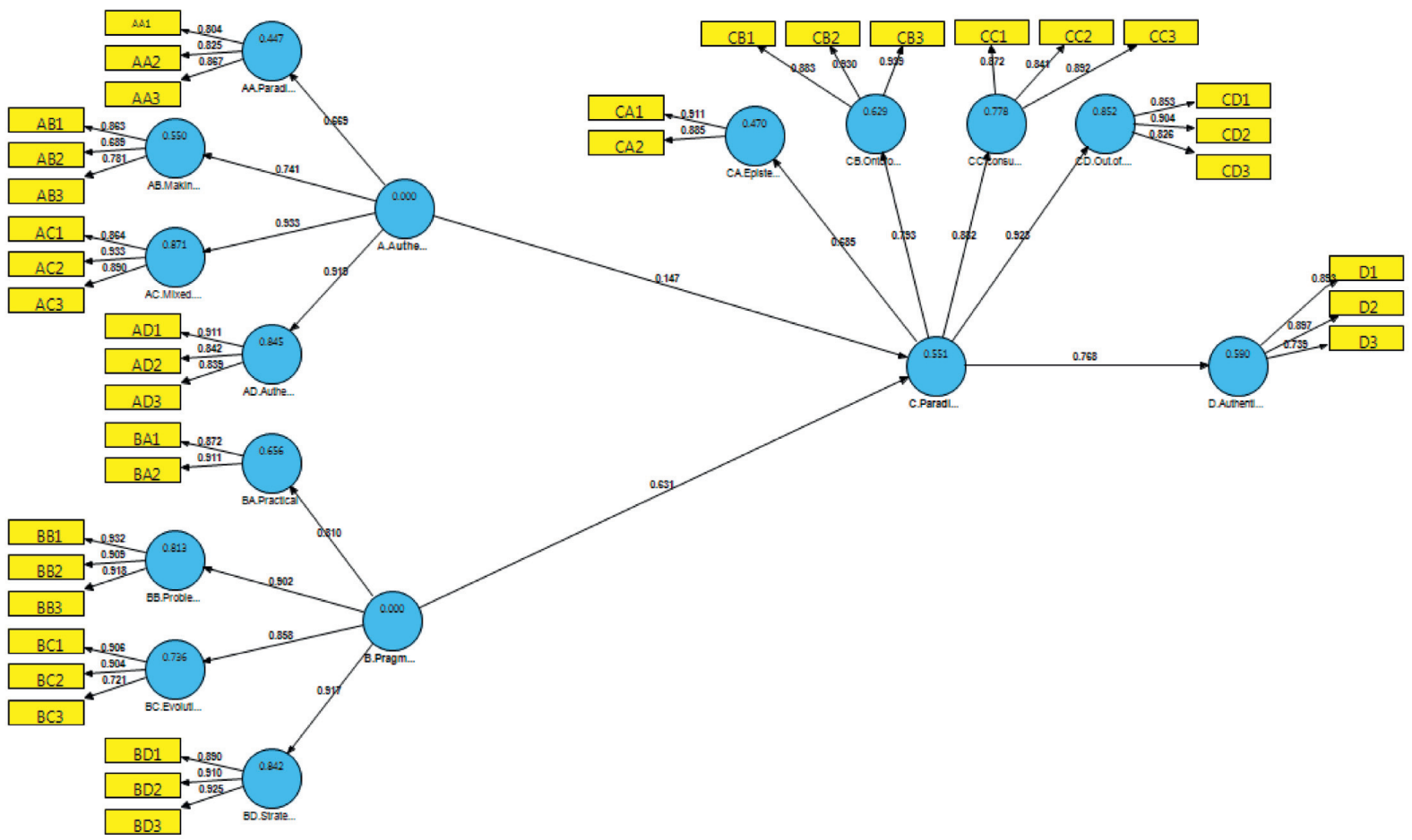

FIGURE 2: The external model of first-order hypothesis in the general standard state.

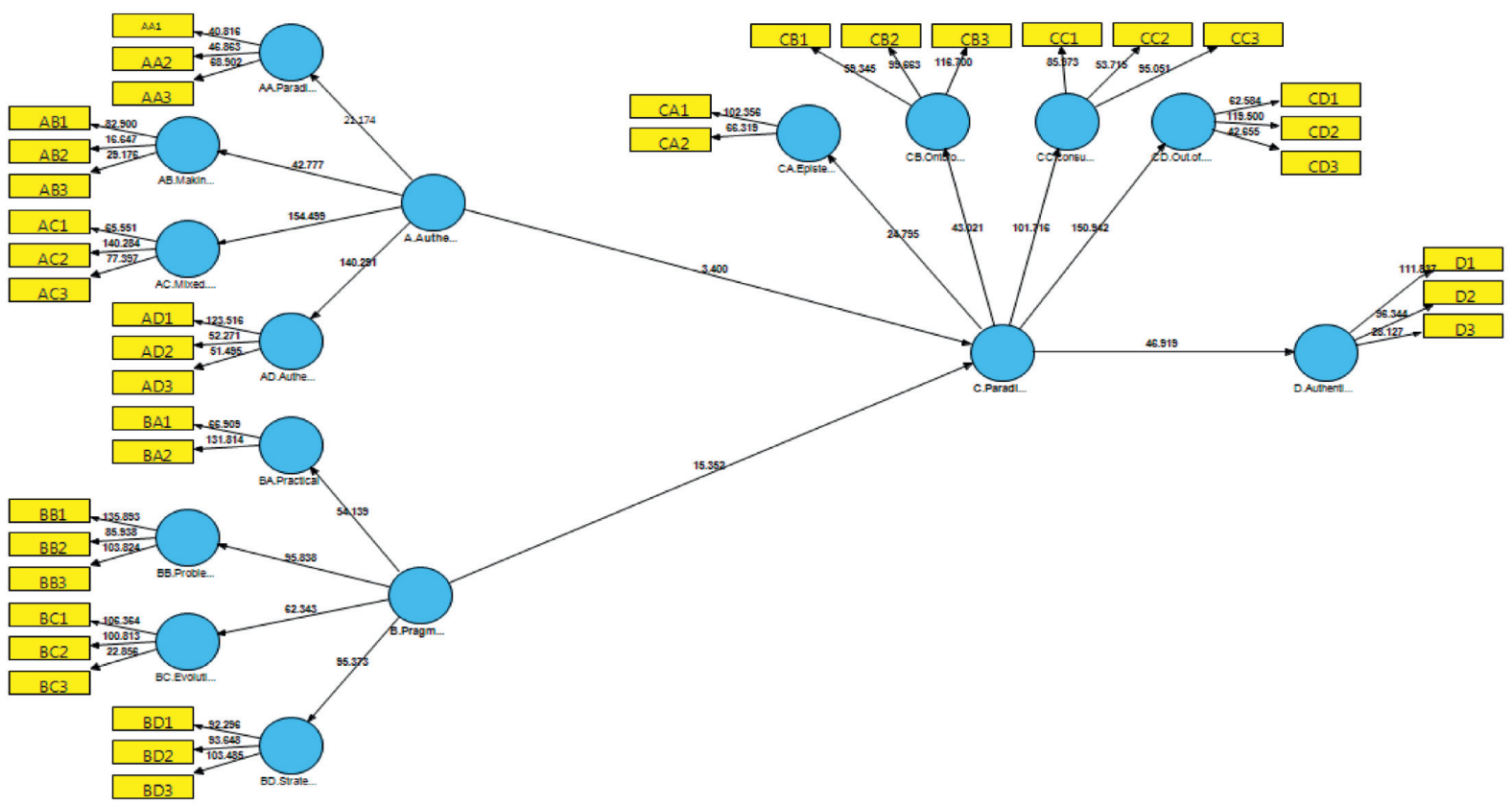

Figure 3: The external model of first-order hypotheses in general significance state.

through changing paradigm shift and there is a need for original marketing with a new ontology to offer genuine value, create new concepts, and enhance the quality of community spirituality.

Hypothesis 2. Pragmatic marketing has a significant effect on the paradigm shift.
H0: pragmatic marketing has no significant effect on the paradigm shift.

H1: pragmatic marketing has a significant impact on the paradigm shift.

The path coefficient of the effect of pragmatic marketing on the paradigm shift is 0.63 and has a $t$ value of 15.35. The $t$ value for this parameter is calculated to be 


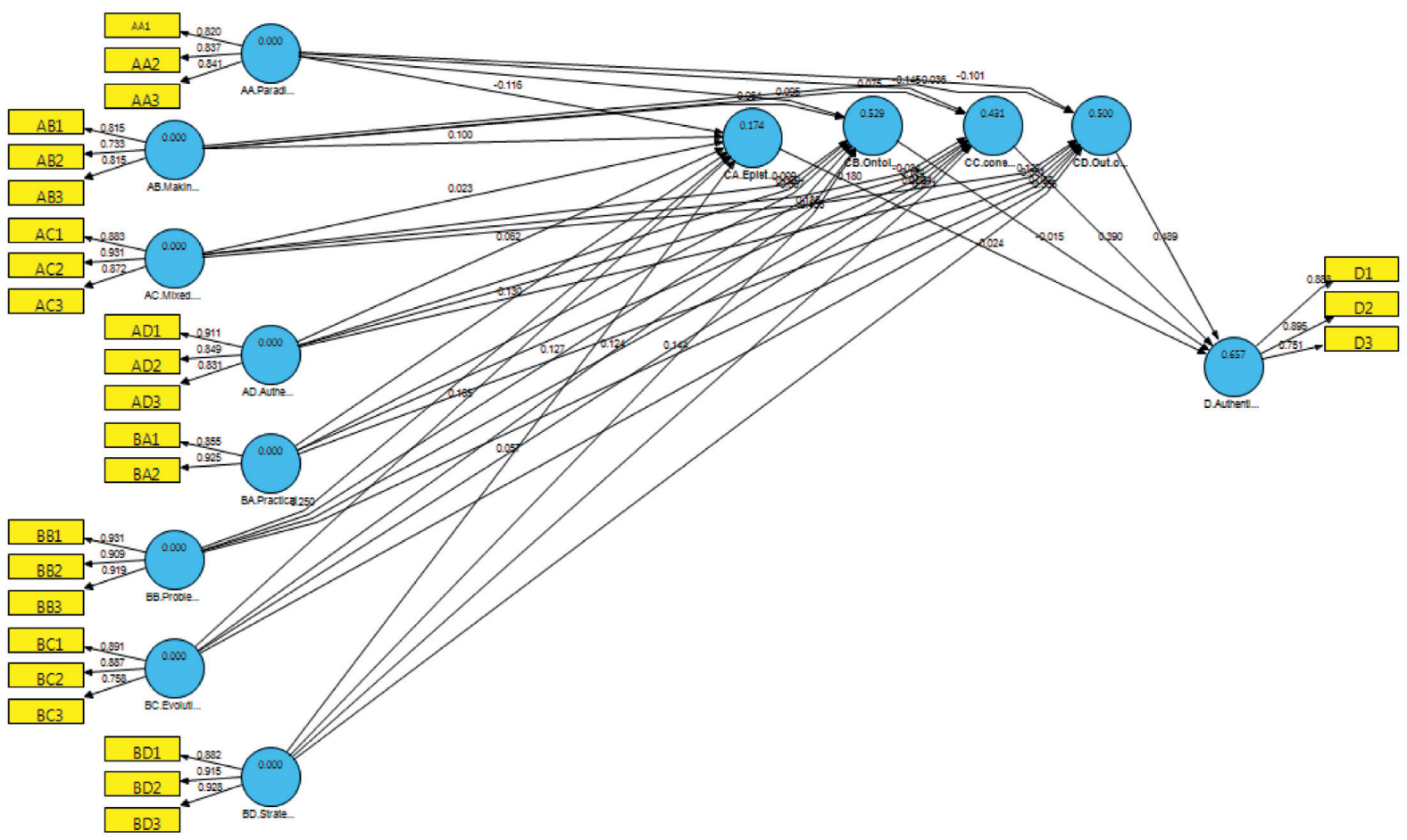

FIgURE 4: The external model of second-order hypotheses in the general standard state.

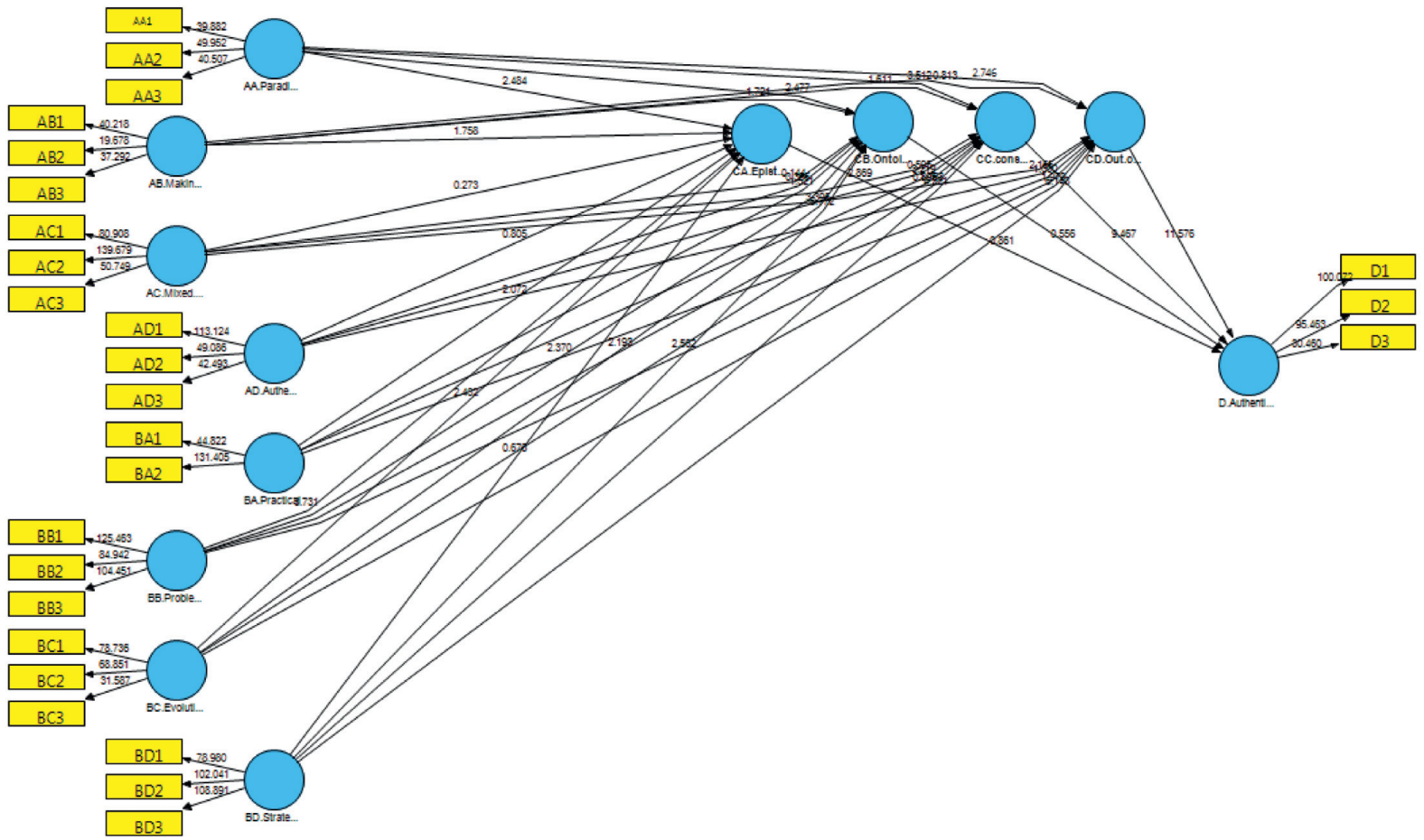

FIgURE 5: The external model of second-order hypotheses in the general significance state.

more than 2.58. Therefore, the null hypothesis is rejected with $99 \%$ confidence. That is, there is a significant relationship between pragmatic marketing and paradigm shift and pragmatic marketing is effective on the paradigm shift. Therefore, this research hypothesis is accepted.
The significant effect of pragmatic marketing on the paradigm shifts is consistent with the research results of Bell and Brown [50] and $\mathrm{He}$ et al. [51] who incorporated the practical attitude of pragmatic marketing to confront the consequences of their beliefs; the problem solving process in the social practice and the reinforcement of science and 


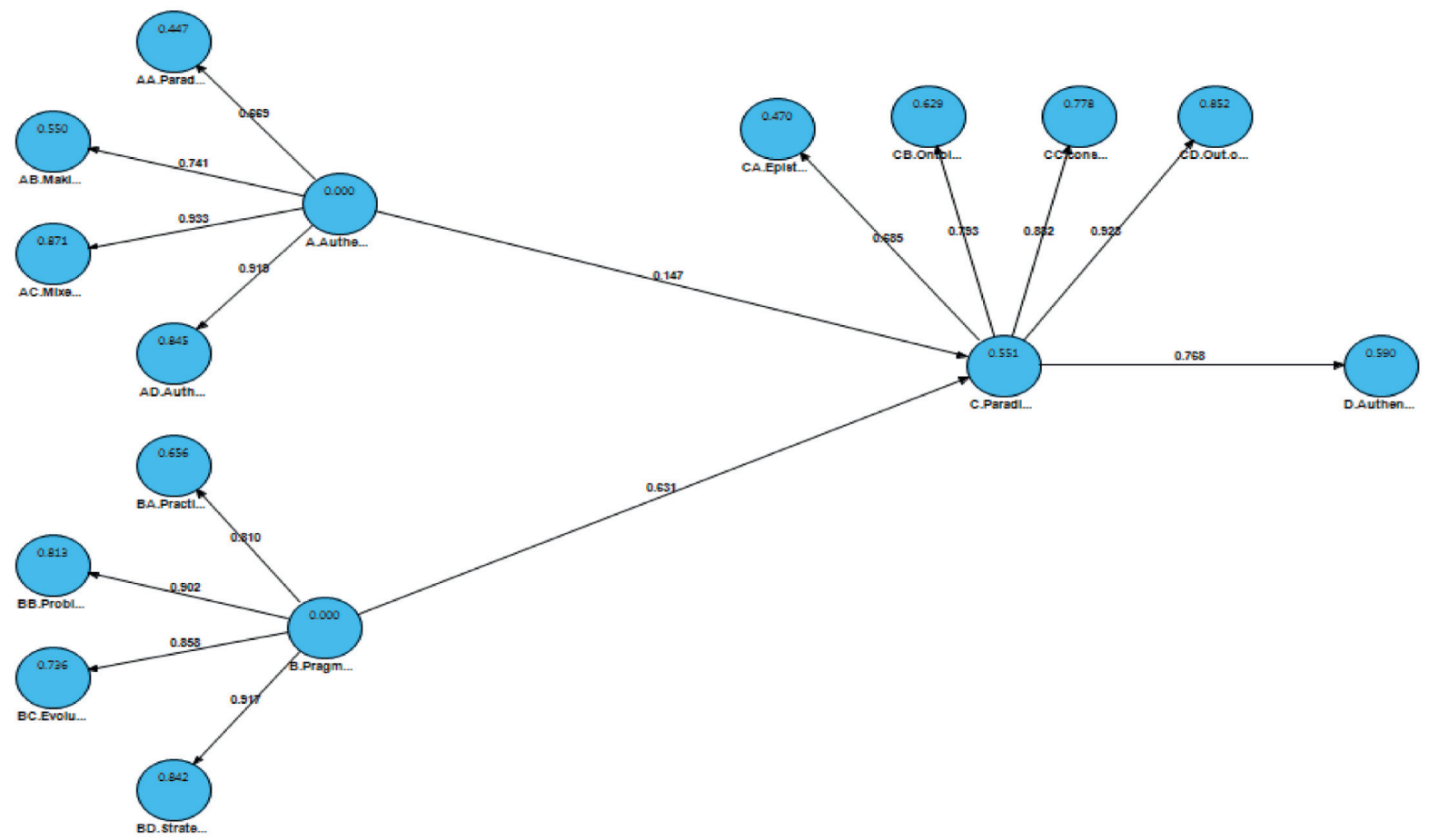

Figure 6: The internal model of first-order hypotheses in the general standard state.

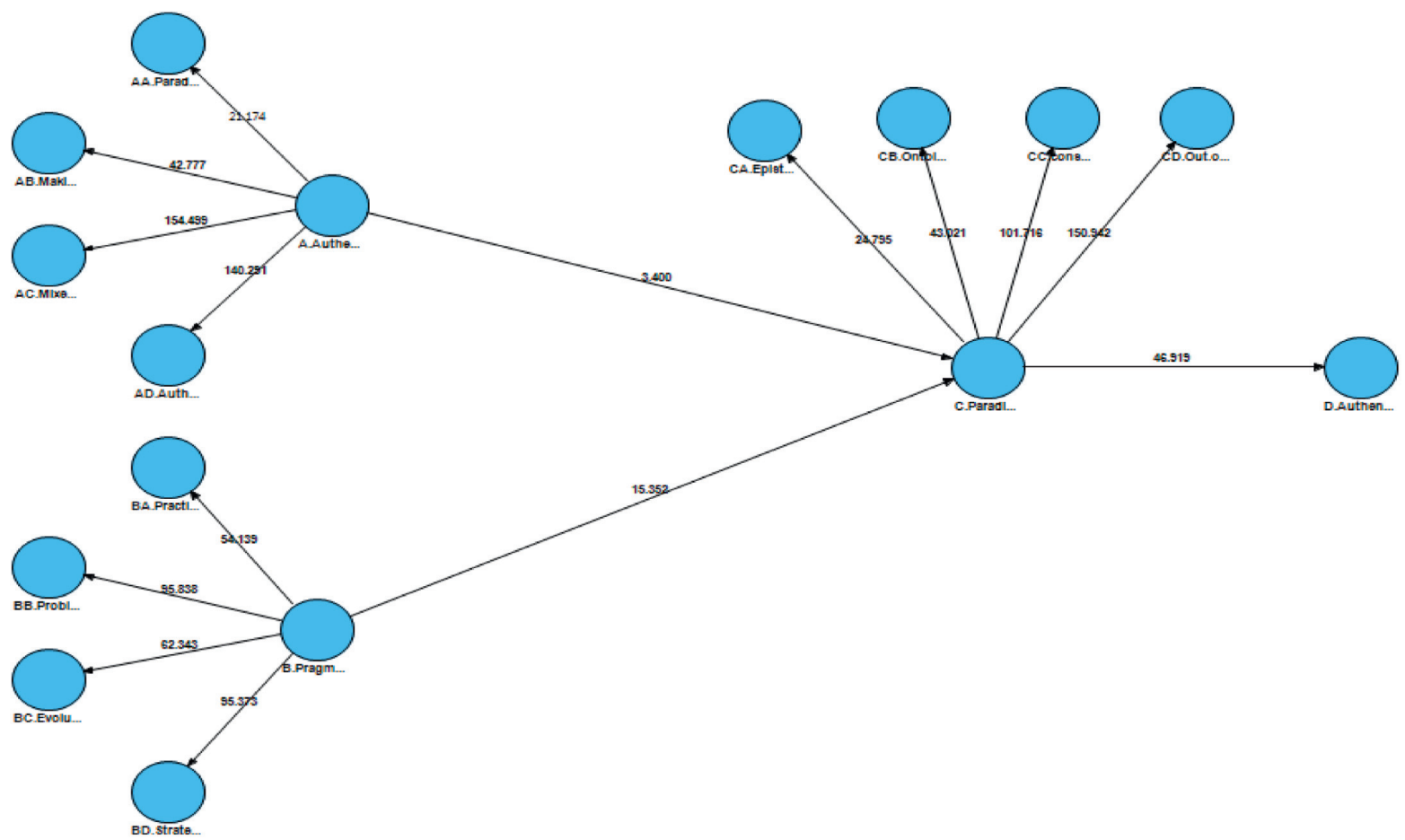

Figure 7: The internal model of first-order assumptions in general significance state.

practice in an interactive approach between university and industry showed that universities will be able to establish a sustainable interaction between philosophy and practice through a paradigm shift in pragmatic marketing, leading to sustainable resource growth.
Hypothesis 3. The paradigm shift has a significant effect on the original brand.

H0: the paradigm shift has no significant effect on the original brand. 


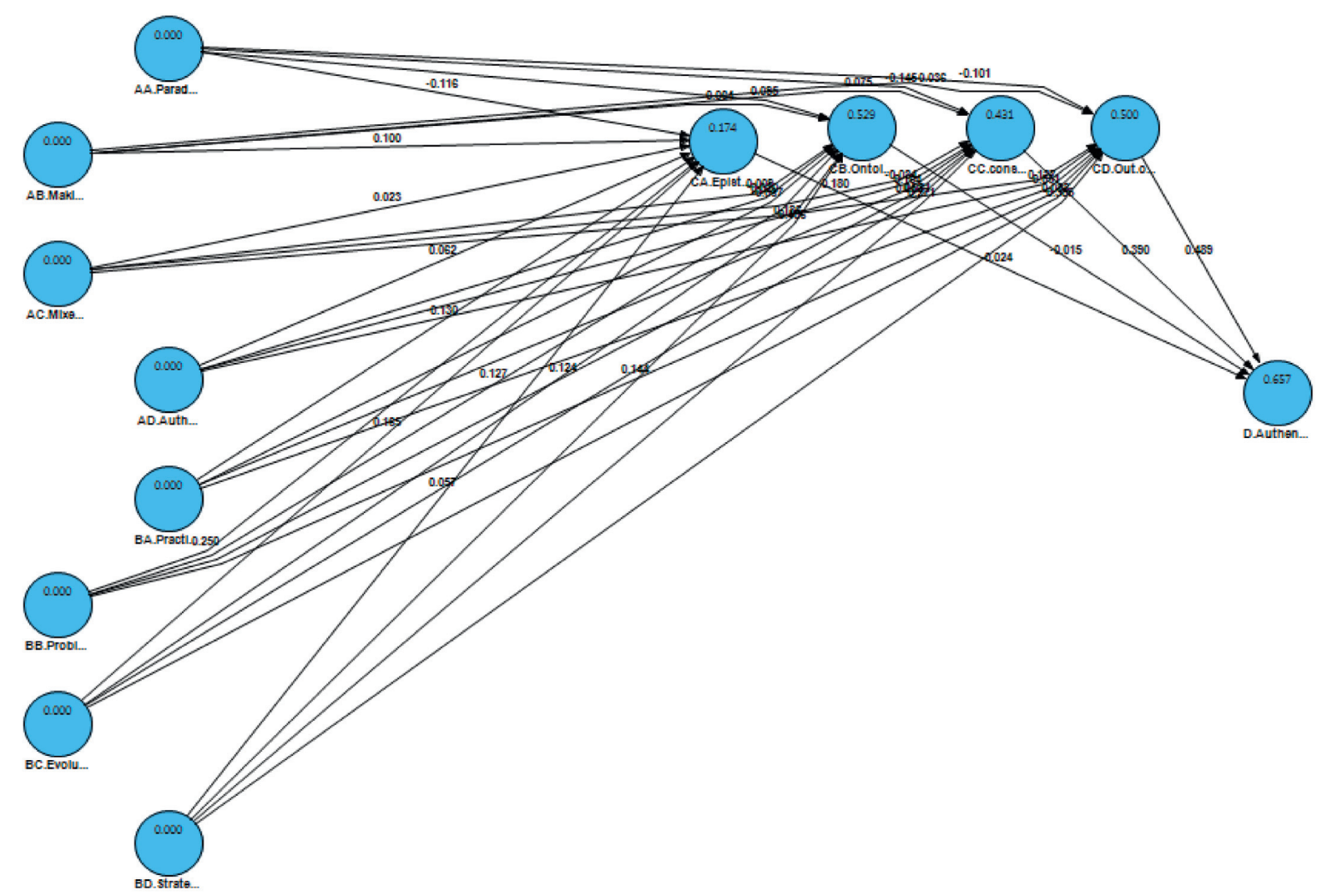

FIGURE 8: The internal model of second-order hypotheses in the general standard case.

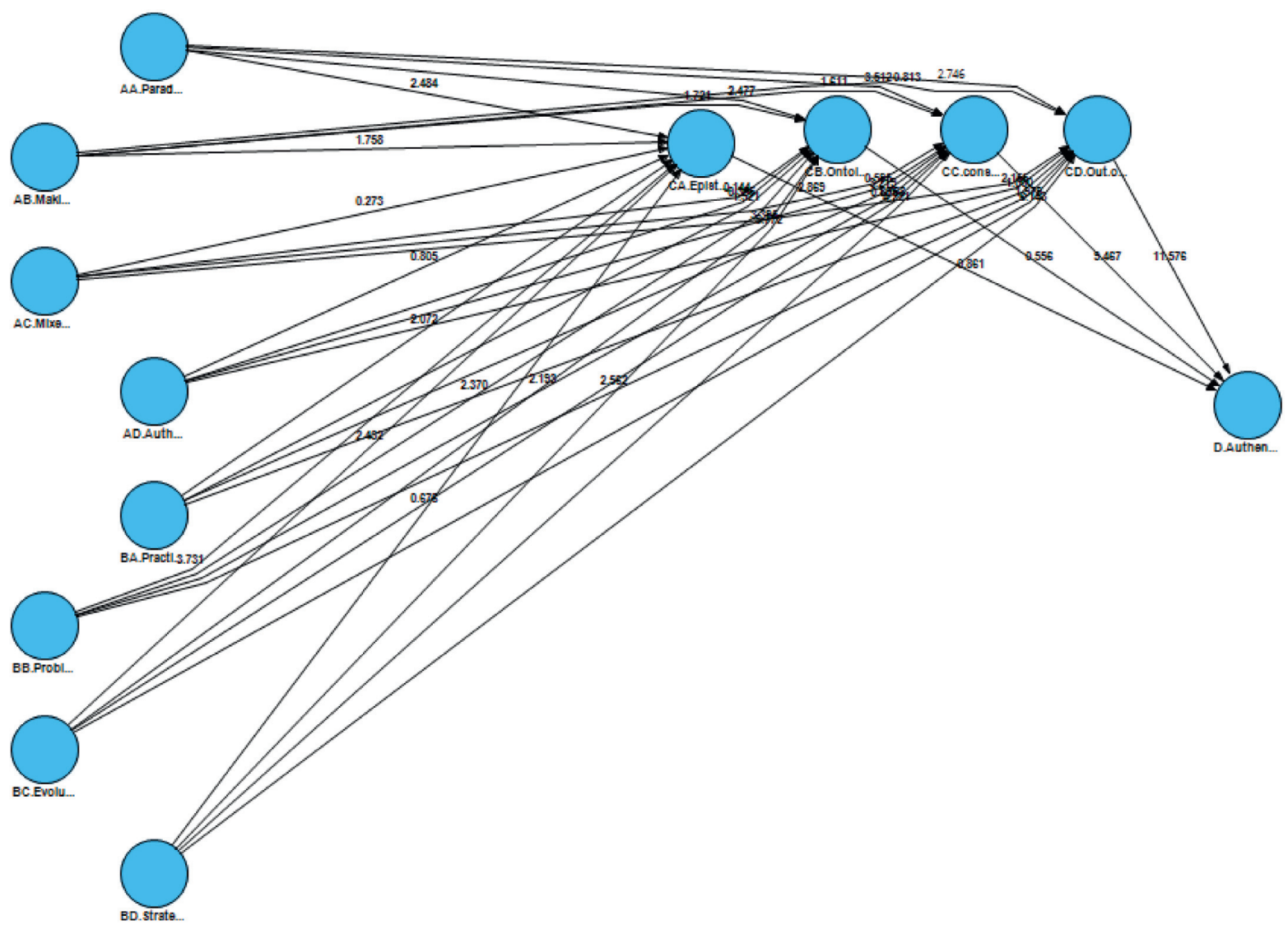

Figure 9: The internal model of second-order hypotheses in the general significance state. 
TABLE 5: Calculation of internal model fitting (first-order analysis).

\begin{tabular}{lcr}
\hline Variable & Communality & $R^{2}$ \\
\hline Authentic marketing & 0.52 & 0.00 \\
Pragmatic marketing & 0.62 & 0.00 \\
Paradigm shift & 0.55 & 0.55 \\
Original brand & 0.72 & 0.59 \\
Goodness of fit index & & 0.59 \\
\hline
\end{tabular}

TABLE 6: Calculation of the fit of the internal model of second-order hypotheses.

\begin{tabular}{lrr}
\hline Variable & Communality & $R^{2}$ \\
\hline Authentic marketing variable & 0.69 & 0.00 \\
Building social platforms & 0.62 & 0.00 \\
Authentic marketing mix & 0.80 & 0.00 \\
Authentic values & 0.75 & 0.00 \\
Pragmatism & 0.85 & 0.00 \\
Problem-oriented & 0.72 & 0.00 \\
Evolutionary product & 0.83 & 0.00 \\
The process of strategic formulation of pragmatic marketing & 0.81 & 0.00 \\
Epistemological change & 0.84 & 0.17 \\
Ontological change & 0.75 & 0.53 \\
Consumer growth & 0.74 & 0.43 \\
Out-of-structure changes & 0.72 & 0.50 \\
Original brand & & 0.66 \\
Goodness of fit index & & 0.59 \\
\hline
\end{tabular}

TABLE 7: Results of partial least squares analysis for first-order research hypotheses.

\begin{tabular}{|c|c|c|c|c|}
\hline $\begin{array}{l}\text { Number of } \\
\text { hypothesis }\end{array}$ & Hypotheses & $\begin{array}{l}\text { Path } \\
\text { coefficients }\end{array}$ & $\begin{array}{l}\text { Significance } \\
\text { value }\end{array}$ & Test result \\
\hline $\mathrm{H} 1$ & Authentic marketing has a significant effect on the paradigm shift. & 0.15 & 3.40 & Confirmed \\
\hline $\mathrm{H} 2$ & Pragmatic marketing has a significant effect on the paradigm shift. & 0.63 & 15.35 & Confirmed \\
\hline H3 & The paradigm shift has a significant effect on the original brand. & 0.77 & 46.92 & Confirmed \\
\hline $\mathrm{H} 4$ & $\begin{array}{l}\text { Original marketing has a significant impact on the original brand with } \\
\text { the mediating role of paradigm shift. }\end{array}$ & \multicolumn{2}{|c|}{0.11} & Confirmed \\
\hline H5 & $\begin{array}{c}\text { Pragmatic marketing has a significant impact on the original brand } \\
\text { with the mediating role of paradigm shift. }\end{array}$ & \multicolumn{2}{|c|}{0.48} & Confirmed \\
\hline
\end{tabular}

TABLE 8: Partial least squares analysis results for second-order research hypotheses.

\begin{tabular}{|c|c|c|c|c|}
\hline $\begin{array}{l}\text { Number of } \\
\text { hypothesis }\end{array}$ & Hypotheses & $\begin{array}{c}\text { Path } \\
\text { coefficient }\end{array}$ & $\begin{array}{c}\text { Significance } \\
\text { value }\end{array}$ & $\begin{array}{c}\text { Test } \\
\text { result }\end{array}$ \\
\hline H6 & $\begin{array}{c}\text { The authentic marketing paradigm has an impact on the ontological } \\
\text { change }\end{array}$ & -0.12 & 2.48 & Accepted \\
\hline H7 & Building social platforms has an impact on ontological change & 0.10 & 1.76 & Rejected \\
\hline $\mathrm{H} 8$ & The original marketing mix has an impact on the ontological change & 0.02 & 0.27 & Rejected \\
\hline H9 & Authentic values has an effect on epistemological change & 0.06 & 0.80 & Rejected \\
\hline $\mathrm{H} 10$ & Pragmatism has an effect on the epistemological change & -0.13 & 2.07 & Accepted \\
\hline H11 & Problem-centeredness has an effect on epistemological change & 0.25 & 3.73 & Accepted \\
\hline $\mathrm{H} 12$ & The evolutionary product has an impact on epistemological change & 0.16 & 2.43 & Accepted \\
\hline $\mathrm{H} 13$ & $\begin{array}{c}\text { The process of strategic formulation of pragmatic marketing has an } \\
\text { impact on epistemological change }\end{array}$ & 0.06 & 0.68 & Rejected \\
\hline $\mathrm{H} 14$ & The original marketing paradigm has an impact on ontology change & 0.10 & 2.48 & Accepted \\
\hline H15 & Building social platforms has an impact on ontological change & 0.06 & 1.72 & Rejected \\
\hline H16 & The authentic marketing mix has an impact on ontological change & 0.01 & 0.14 & Rejected \\
\hline H17 & Authentic values have an impact on ontological change & 0.02 & 0.36 & Rejected \\
\hline $\mathrm{H} 18$ & Pragmatism has an effect on ontological change & -0.07 & 1.52 & Rejected \\
\hline H19 & Problem-centeredness has an effect on ontological change & 0.13 & 2.37 & Accepted \\
\hline
\end{tabular}


TABLE 8: Continued.

\begin{tabular}{|c|c|c|c|c|}
\hline $\begin{array}{l}\text { Number of } \\
\text { hypothesis }\end{array}$ & Hypotheses & $\begin{array}{c}\text { Path } \\
\text { coefficient }\end{array}$ & $\begin{array}{l}\text { Significance } \\
\text { value }\end{array}$ & $\begin{array}{c}\text { Test } \\
\text { result }\end{array}$ \\
\hline $\mathrm{H} 20$ & The evolutionary product has an effect on ontological change & 0.19 & 3.40 & Accepted \\
\hline $\mathrm{H} 21$ & $\begin{array}{c}\text { The process of strategic formulation of pragmatic marketing has an effect } \\
\text { on ontological change }\end{array}$ & 0.41 & 5.77 & Accepted \\
\hline $\mathrm{H} 22$ & The original marketing paradigm has an impact on consumer growth & -0.14 & 3.51 & Accepted \\
\hline $\mathrm{H} 23$ & Building social platforms has an impact on consumer growth & 0.07 & 1.61 & Rejected \\
\hline $\mathrm{H} 24$ & Authentic marketing mix has an impact on consumer growth & 0.18 & 2.87 & Accepted \\
\hline $\mathrm{H} 25$ & Authentic values have an effect on consumer growth & -0.03 & 0.59 & Rejected \\
\hline $\mathrm{H} 26$ & Pragmatism has an impact on consumer growth & 0.16 & 3.22 & Accepted \\
\hline $\mathrm{H} 27$ & Problem-centeredness has an impact on consumer growth & 0.12 & 2.19 & Accepted \\
\hline $\mathrm{H} 28$ & The evolutionary product has an impact on consumer growth & 0.08 & 1.76 & Rejected \\
\hline $\mathrm{H} 29$ & $\begin{array}{l}\text { The process of strategic formulation of pragmatic marketing has an } \\
\text { impact on consumer growth }\end{array}$ & 0.27 & 4.22 & Accepted \\
\hline $\mathrm{H} 30$ & $\begin{array}{c}\text { The authentic marketing paradigm has an effect on out-of-structure } \\
\text { changes }\end{array}$ & -0.10 & 2.75 & Accepted \\
\hline $\mathrm{H} 31$ & Building social platforms has an effect on out-of-structure changes & 0.04 & 0.81 & Rejected \\
\hline $\mathrm{H} 32$ & Authentic marketing mix has an effect on out-of-structure changes & 0.05 & 0.89 & Rejected \\
\hline $\mathrm{H} 33$ & Authentic values has an effect on out-of-structure changes & 0.13 & 2.15 & Accepted \\
\hline $\mathrm{H} 34$ & Pragmatism has an effect on out-of-structure changes & 0.05 & 1.00 & Rejected \\
\hline H35 & Problem-centeredness has an effect on out-of-structure changes & 0.14 & 2.56 & Accepted \\
\hline H36 & Evolutionary product has an effect on out-of-structure changes & 0.09 & 1.98 & Accepted \\
\hline H37 & $\begin{array}{c}\text { The process of strategic formulation of pragmatic marketing has an effect } \\
\text { on out-of-structure changes }\end{array}$ & 0.38 & 6.14 & Accepted \\
\hline $\mathrm{H} 38$ & Epistemological change has an effect on the authentic brand & -0.02 & 0.86 & Rejected \\
\hline H39 & Ontology change has an effect on the authentic brand & -0.02 & 0.56 & Rejected \\
\hline $\mathrm{H} 40$ & Consumer growth has an effect on the authentic brand & 0.39 & 9.47 & Accepted \\
\hline $\mathrm{H} 41$ & Out-of-structure changes have an effect on the authentic brand & 0.49 & 11.58 & Accepted \\
\hline
\end{tabular}

$\mathrm{H1}$ : the paradigm shift has a significant impact on the original brand.

The path coefficient of the effect of paradigm shift on the original brand is 0.77 and has a $t$ value of 46.92 . The $t$ value for this parameter is calculated to be more than 2.56 . Therefore, the null hypothesis is rejected with $99 \%$ confidence. That is, there is a significant relationship between the paradigm shift and the original brand and the paradigm shift does not affect the original brand. Therefore, this research hypothesis is accepted.

Significance of paradigm shift's effect on original brand is consistent with research results of Ferasatkhah [8] on the need to change paradigm shift when relationship regulation comes with epistemic crisis, and it shows that changing the paradigm shift of the selected universities can add to their brand authenticity and contribute to their sustainable value creation.

Hypothesis 4. Authentic marketing has a significant impact on the original brand with the mediating role of paradigm shift.

H0: original marketing does not have a significant impact on the original brand with the mediating role of paradigm shift.

$\mathrm{H} 1$ : original marketing has a significant impact on the original brand with the mediating role of paradigm shift.

Given the confirmation of the first path, i.e., the effect of original marketing on the paradigm shift, as well as the confirmation of the second path, i.e., the effect of the paradigm shift on the original brand, all paths related to this hypothesis have been confirmed; therefore, the null hypothesis is rejected with $95 \%$ confidence. That is, authentic marketing has a significant impact on the original brand with the mediating role of paradigm shift. Therefore, the paradigm shift variable plays a mediating role here. Moreover, the effect of original marketing with the mediating role of paradigm shift on the original brand is 0.11 .

The significant impact of authentic marketing by shift paradigm on original brand is consistent with the research results of Gharabagh [29] and Shiroudi [30] in relation to the phenomenological effect of philosophical hermeneutics on deep understanding of phenomena and their asymmetry in existence and the creation of transcendental concepts based on the lived experience of each person, through hermeneutic understanding of concepts in dialectics based on language. On this basis, the selected universities can change their ontology to the phenomenology of existence and dialectics in the concepts that are effective in shaping their original brand content.

Hypothesis 5. Pragmatic marketing has a significant impact on the original brand with the mediating role of paradigm shift.

H0: pragmatic marketing does not have a significant impact on the original brand with the mediating role of paradigm shift.

H1: pragmatic marketing has a significant impact on the original brand with the mediating role of paradigm shift. 
Given the confirmation of the first path, i.e., the impact of pragmatic marketing on the paradigm shift, and the second path confirmation, i.e., the effect of the paradigm shift on the original brand, all paths related to this hypothesis have been confirmed, so the null hypothesis is rejected with 95\% confidence. That is, pragmatic marketing has a significant impact on the original brand with the mediating role of paradigm shift. Therefore, the paradigm shift variable plays a mediating role here. Therefore, the effect of pragmatic marketing with the mediating role of paradigm shift on the original brand is 0.48. Significance of pragmatic marketing through paradigm shift of the original brand is consistent with the research results of Heidari [42] and Hatami Nejad et al. [36] which considers the dialectical and progressive view as a social, ever-changing, and evolving phenomenon. They have always been negative and replaced by positive, progressive, and revolutionary elements. Universities can recognize the negative practical consequences of the theories and target them to increase the utility of society by shifting the paradigm shift to the phenomenology of existence and the dialectics of science and practice between academia and industry.

Significance of hypotheses $10,11,12,19,20,21,26,27$, $29,37,36$, and 35 is consistent with research results obtained by Hatami Nejad et al. [36] and Anderson [55]; pragmatic marketing should address the problems of the community and improve the current state of society. It is also consistent with Nutinsky Pragmatic Marketing Strategic Marketing Planning Form [39] and the Pragmatic Institute [37]. Similarly, selected universities can produce evolutionary products to respond to economic, social, and cultural problems by strategically planning pragmatic marketing.

The hypotheses $13,18,28$, and 34 are not consistent with the results of Anderson [55], Zandieh [56], and Hatami Nejad et al. [36]. Pragmatism means theoretical reasoning, and it suggests that pragmatism does not necessarily have ontological change in the studied community. And social change as well as evolutionary product has no significant relationship with consumer growth, in which case more research is needed.

The significance of hypotheses 40 and 41 is consistent with research results of Sarokhani and Abdolmaleki [57] regarding the increase and interference of channels of comprehensiveness in the new technology era that imposes conditions of out-of-structure changes on societies. Society faces multiple valuations that dispute credits such as authenticity and disbelief. It is also consistent with research results obtained by Zickmund [2, 28] that in the current age, when word of mouth has become a new medium, consumers trust strangers in their community more than corporations. Businessmen without authenticity will have no chance of survival. On this basis, it is recommended that selected universities plan to increase their authenticity based on continuous and sustained interaction with the students in order to gain more existence due to consumer growth in value sharing and increasing conflict of value socialization channels.

\section{Conclusions}

Since the customer trust in brands has diminished and the validity of the value presented by the brand has been decreased, achieving brand authenticity is essential to producing sustainable value. Given that in the new technology era, vertical communication has transformed marketers and customers into horizontal communications and that their creators and marketers have been competing with them, engaging more customers in the value chain of the company and adding brand authenticity have led the organizations to produce goods of sustainable value.

Marketing with phenomenological ontology is a kind of postmodern marketing, and its methodology is a combination of structured and semistructured methods.

On the other hand, by reducing the quality, increasing the orientation of the universities and the degree of community orientation that results in the decrease of the level of culture and the growth of the society, the purpose of this research is to show that in the age of globalization, new generation technology and communication rationality, universities To achieve brand authenticity, what can produce sustainable value requires paradigm shifts in ontology and epistemology in their view of students, and to be phenomenological rather than object and commodity, and seek through sustained interaction with them to gain their inner creativity and experience so that they can generate value and culture in the community which can creat a sustainable growth.

Elements of paradigm shift, namely, consumer growth and out-of-structure changes, affect brand authenticity, so universities can create the atmosphere of emergence and emergence of students' talent and their ongoing engagement with themselves, with industry, society, and culture until they can manage the out-of-structure changes and guide it towards social, cultural, and spiritual alternatives.

The goal of changing ontological view in university is to avoid considering the customer as an instrument; getting internal experience, creativity, and sustained customer interaction are key to sustainable knowledge development. Sustainable value production is not separate from economic growth, but it sustains growth, and this paradigm shift, while developing the knowledge economy, affects the quality of university-produced product, making it a prominent and authentic cultural institution, because brand originality has content in social interaction.

7.1. Limitation. This research studied the students of the selected Islamic Azad universities, because it is the first study on the interaction of the main and pragmatic marketing in the country and because of the researcher's limitation to study all social groups in Iran

\section{Data Availability}

No data were used to support this study. 


\section{Conflicts of Interest}

The authors declare that they have no conflicts of interest.

\section{References}

[1] M. Haghighi, K. Masoud, and B. Zadeh Eliya, "Customer's Trust to Large Store Personnel: a study in chain store clients," in Study in Chain stores in Shahrvand Tehran, vol. 8, no. 3, Management Sciences Association, Pittsburgh, PA, USA, 2013.

[2] P. Kotler, H. Kartajaya, and I. Setiawan, Marketing 3.0: From Products to Customers to the Human Spirit, John Wiley \& Sons, Hoboken, NJ, USA, 2010.

[3] J. N. Sheth and R. S. Sisodia, "Does marketing need reform?" Fresh Perspectives on the Future, M.E. Sharpe Inc., Armonk, NY, USA, 2004.

[4] G. T. Barrett-Lennard, Carl Rogers' Helping System: Journey and Substance, SAGE Publications, Thousand Oaks, NY, USA, 1998.

[5] M. Maljoo, Iran's Economic Outlook, Iran Steel News Agency, Tehran, Iran, 2016.

[6] E. Salehi Omran, "Employment status of female graduates: a case study," Research and Planning in Higher Education Spring 2006, Scientific/ISC, no. 39, pp. 41-60, Paris, France, 2006.

[7] M. Feraskhah, Socio-economic Development. Communication and its Relationship with Scientific Development, Heavenly Institute, Atlanta, Georgia, 2003.

[8] M. Ferasatkhah, Qualitative Research Method in Social Sciences Based on "Theory Based, Agah Publication, Brasil, France, 2016.

[9] Oxford English Dictionary, Prepared by Leeder, K, Oxford University Press, Oxford, UK, 2019.

[10] J. H. Gilmore and B. J. Pine, Authenticity: What Consumers Really Want?, Harvard Business School Press, Boston, MA, USA, 2007.

[11] G. Cappannelli, Authenticity: Simple Strategies for Greater Meaning and Purpose at Work and at Home, Clerisy Press, Covington, KY, USA, 2004.

[12] J. Neapoli, S. J. Dickinson, M. B. Beverland, and F. Farrelly, "Measuring consumerbased brand authenticity," Journal of Business Research, vol. 67, no. 6, pp. 1090-1098, 2014.

[13] F. Mourhart, L. Malar, A. Guevremont, F. Girardin, and B. Grohmann, "Brand authenticity: an integrative framework and measurement scale," Journal of Consumer Psychology, vol. 25, no. 2, pp. 200-218, 2015.

[14] M. B. Beverland and F. J. Farrelly, "The quest for authenticity in consumption: consumers'purposive choice of authentic cues to shape experienced outcomes," Journal of Consumer Research, vol. 36, no. 5, 2010.

[15] M. B. Beverland, A. Lindgreen, and M. W. Vink, "Projecting authenticity through advertising: consumer judgments of advertisers' claims," Journal of Advertising, vol. 37, no. 1, pp. 5-15, 2008.

[16] E. J. Arnould and L. L. Price, "Authenticating acts and authoritative performances. Questing for self and community," in The Why of Consumption, S. Ratneshwar, D. G. Mick, and C. Huffman, Eds., Cambridge University Press, Cambridge, UK, 2000.

[17] C. J. Thompson, "Interpreting consumers: a hermeneutical framework for deriving marketing insights from the texts of consumers' consumption stories," Journal of Marketing Research, vol. 34, pp. 438-445, 1997.

[18] J. L. Davis, Accomplishing Authenticity in a Labor-Exposing Space, Elsevier, Amsterdam, Netherlands, 2017.
[19] D. B. Holt, How Brands Become Icons: The Principles of Cultural Branding, Harvard Business School Press, Boston, MA, USA, 2004.

[20] H. Gholipour, "From Weber to Habermas about Science and Values, Robert Hollinger," Humanities Psychology Magazine, vol. 48, 2007.

[21] B. Cova, "From marketing to societing: when the link is more important than the thing," in Rethinking Marketing: Towards Critical Marketing Accountings, D. T. Brownlie, R. Wensley, and R. Whittington, Eds., pp. 64-83, Sage Publications, Thousand Oaks, NY, USA, 1999.

[22] N. Wang, "Rethinking authenticity in tourism experience," Annals of Tourism Research, vol. 26, no. 2, pp. 349-370, 1999.

[23] C. J. Steiner and Y. Reisinger, "Understanding existential authenticity," Annals of Tourism Research, vol. 33, no. 2, pp. 299-318, 2006.

[24] K. Olsen, "Authenticity as a concept in tourism research," Tourist Studies, vol. 2, no. 2, pp. 159-182, 2002.

[25] S. Sen, C. B. Bhattachar, and D. Korschun, "The role of corporate social responsibility in strengthening multiple stakeholder relationships: a field experiment," Journal of The Academy of Marketing Science, vol. 34, no. 2, 2006.

[26] J. C. Aker, M. W. Klein, S. A. O'Connell, and M. Yang, "Borders, ethnicity and trade," Journal of Development Economics, vol. 107, pp. 1-16, 2014.

[27] F. Eggers, M. O’Dwyer, S. Kraus, C. Vallaster, and S. Güldenberg, "The impact of brand authenticity on brand trust and SME growth: a CEO perspective," Journal of World Business, vol. 48, no. 3, pp. 340-348, 2013.

[28] S. Zickmund, "Deliberation, phronesis and authenticity: Heidegger's early conception of rhetoric," Philosophy \& Rhetoric, vol. 40, no. 4, pp. 406-415, 2007.

[29] G. Gharabagh and Ahmad, "Gadamer's philosophical hermeneutics in critique," Journal: Ma'rifat, vol. 128, pp. 99-112, 2008.

[30] M. Shiroudi, "The study and methodology of political science," Journal of Religion and Politics, Work and at Home, Clerisy Press, Covington, KY, USA, 2009.

[31] L. D. Hollebeek and K. Macky, "Digital content marketing's role in fostering consumer engagement, trust, and value: framework, fundamental propositions, and implications," Journal of Interactive Marketing, vol. 45, 2019.

[32] G. Parker and M. Van Alstyne, "Six challenges in platform licensing and open innovation," Communication Strategies Q2, vol. 74, pp. 17-36, 2009.

[33] A. Richter and M. Koch, "Social software-status quo und Zukunft," Technischer Bericht, 2007.

[34] A. M. Kaplan and M. Haenlein, "Users of the world, unite! the challenges and opportunities of social media," Business Horizons, vol. 53, no. 1, pp. 59-68, 2010.

[35] F. Ferahbod and M. Yousefinia, Marketing in Postmodern Language, Humanities and Cultural Studies Institute, no. 215, Tehran, Iran, 2010.

[36] H. Hatami Nejad, A. Saraskanrood, and Mohammad, "Pragmatism," Geographical Information Journal, vol. 79, 2011.

[37] E. Freeman and R. Philips, Bussiness Ethics: Postmodernism and Pragmatism, A Companion to Business Ethics, Wiley, Hoboken, NJ, USA, 1999.

[38] J. Wamicha, "Software defined radio OFDM implementation, mixed signal circuit design and EBG antenna design," University of Cape Town, Cape Town, South Africa, MSc dissertation, 2018. 
[39] R.. Nutinsky, Building Effective Product Roadmaps, Pragmatic Marketing, Inc., Scottsdale, Arizona, 2007.

[40] T. S. Kuhn, The Structure of Scientific Revolution, University of Chicago Press, Chicago, IL, USA, 4th edition, 1962.

[41] T. Kolar and V. Zabkar, "A consumer-based model of authenticity: an oxymoron or the foundation of cultural heritage marketing?" Tourism Management, vol. 31, no. 5, pp. 652-664, 2010.

[42] H. Heidari, Habermas in the Battle with Modern Epistemic Crisis, Communicative Rationality Instead of Instrumental Rationality, Vol. 33, Institute for Humanities and Cultural Studies, Tehran, Iran, 2004.

[43] Z. Aliesmaeili and B. Kheiri, "Authentic marketing pragmatic marketing (components, foregrounds, outcomes): interactions \& conflicts," Journal of Marketing Management, vol. 13, no. $40,2019$.

[44] M. R. Hafeznia, Introduction to Research Methods in the Humanities, Samat Publishing, Villeneuve-les-Maguelone, France, 2016.

[45] B. P. Wilcox, M. K. Owens, W. A. Dugas, D. N. Ueckert, and C. R. Hart, "Shrubs, streamflow, and the paradox of scale," Hydrological Processes, vol. 20, no. 15, pp. 3245-3259, 2006.

[46] J. C. Nunnally and I. H. Bernstein, "The assessment of reliability," Psychometric Theory, vol. 3, pp. 248-292, 1994.

[47] W. Chin, "The partial least squares approach to structural equation modeling," Advances in Hospitality and Leisure, vol. 8, no. 2, 1998.

[48] R. Wetzels, J. G. W. Raaijmakers, E. Jakab, and E.-J. Wagenmakers, "How to quantify support for and against the null hypothesis: a flexible WinBUGS implementation of a default Bayesian t test," Psychonomic Bulletin \& Review, vol. 16, no. 4, pp. 752-760, 2009.

[49] J. G. Moulard, C. P. Garrity, and D. H. Rice, "What makes a human brand authentic? Identifying the antecedents of celebrity authenticity," Psychology \& Marketing, vol. 32, no. 2, pp. 173-186, 2015.

[50] J. Bell and S. Brown, "Pragmatic perspectives in international marketing education," Journal of Management Development, vol. 9, no. 1, pp. 39-50, 1990.

[51] M. He, J. Li, B. Shao, T. Qin, and Ch Ren, "Transforming massive data to pragmatic target marketing practice," IBM Research, Armonk, NY, USA, 2013.

[52] P. Frosh, "To thine own self be true: the discourse of authenticity in mass cultural production," The Communication Review, vol. 4, no. 4, pp. 541-557, 2001.

[53] D. Zohar and I. Marshall, Spiritual Capital: Wealth We Can Live by, Barrett_Koehler Publisher, San Francisco, CA, USA, 2004.

[54] R. Dragon, Social Marketing Improve Your Social Media Processes and Get Your Customer to Stay Forever, eBook, 2012.

[55] D..r. Anderson, "Business ethics and the pragmatic attitude," A Companion to Business Ethics, Blackwell Publishers Ltd., Hobooken, NJ, USA, 1999.

[56] A. Zandieh, The Pragmatism of Charles Pierce Sanders, M.Sc thesis, Shahid Beheshti University, Tehran, Iran, 1996.

[57] B. Sarokhani and J. Abdolmaleki, Sociological Investigation of the Role of Mass Media in the Environmental Socialization of Adolescents in Tehran (Case Study of Islamic Republic of Iran), Twenty-third Spring Communication Research, vol. 1, 2016. 